\title{
BOOK REVIEW \\ UNBOXING THE DYNAMICS OF LAND AND NATURAL RESOURCE MANAGEMENT IN INDONESIA
}

Anne Booth, Chris Manning, and Thee KianWie, Land, Livelihood, the Economy and the Environment in Indonesia: Essays in Honour of Joan Hardjono (Jakarta, Yayasan Pustaka Obor, 20I2)

This book is a compilation of essays to commemorate Joan Hardjono, an Australian-born scholar who had a great interest in issues of rural development and wellbeing in Indonesia. Following her passion and her love for Indonesia, she contributed greatly to research about rural Indonesia,notably the transmigration program. The chapters presented in this book are written by a wide variety of scholars who share the same interest and concerns over poverty and development. They explore how different aspects of development on land, livelihoods, the economy and the environment have actually changed or improved the conditions of local people in rural areas. This review attempts to provide a brief summary of each chapter of this book and to review the picture of the development of rural Indonesia that it depicts.

Initially, the book introduces a short biography of Joan Hardjono.It follows her career path from the very beginning,how she developed a strong interest in rural Indonesia and concerns about the elusiveness of the country's macroeconomic and community empowerment programs. This chapter outlines Joan's contribution to the development of research in Indonesia specifically on issues of poverty and rural changes as well as her affiliation with numerous aid agencies and local research organizations, now widely knownas AKATIGA and SMERU.

For those who are seeking the history of democracy in Indonesia will find Chapter 2 enjoyable. The authorsclearly introducevarious definitions of democracy and the processes of setting up democratic institutions in Indonesia which were significantly affected by the colonial period. The chapter goes further in elaborating on the history of democracy after Independence where, in the spirit of democracy, the government structure in rural areas was organized withthe village or "desa" as the basisdespite the existence of other forms of "desa" such as keuciksor nagari.It was then questioned whether "desa" actually represented democracy for the community at the lowest level,including adat communities as well as to be able to reach out the poor. In connection with the formal government structure, this chapter outlines concernson whether or not natural resources, a vital asset of Indonesia, and the civil rights of local people have been well managedby the government agencies.

Chapter 3 reflects Joan Hardjono's special interest in environmental issues and her involvement in debates around land use and agrarian change issues. Back in the I980s it was not an easy task to voice the need for environmental conservation when Indonesia was shifting into a high gear on economic development. The chapter emphasizes that, ironically, the complexities of forest land use are still inherent today. The forest management regime in Indonesia was clearly detailed and divided into four important periods; starting from the birth of the Republic of Indonesia until the present. The chapter thenunderlines the existing domination of national forest 
policies, which, despite having moved from a centralized to a decentralized government, favour higher income generationat the expense of forest conservation, hence, rapid deforestation. The dynamics of land use conversion from forest intooil palm plantation and mining among others, overlapping regulations between government departments and the lack of coordination at all levels are meticulously described in this chapter.Particular concernsare raised on the unequal economic benefit distribution from land use conversion among Indonesian people, especially local people whowere dependent on the forest for their livelihood. Lastly, the chapter details the role of thelndonesian government in enforcing forest-related policies and forest conservation programs such as REDD+ (Reducing Emission from Deforestation and Forest Degradation) which have led to some progress e.g. transparency and local community involvement, but also show that there are still many issues to resolve.

Relevantto Chapter 3 but taking on a different point of view, this timefrom the agricultural sector, Chapter 4 analyses the underlying factors of Indonesia's agricultural growth, including palm oil, and its contribution to Indonesia's income. Intriguingly structured as I2 questions and answers, the chapter covers both the macroeconomic and the microeconomic pictures of the agricultural sector. It starts by explaining the dynamics of agricultural growth in Indonesia over the 45 years since the I96os by comparing Java and areas outside Java. The chapter raises the question of whether or not agricultural growth actually causes trade-offswith forest conservation and if it leads to outcomes such as deforestation. The chapter brings us inside the challenges in untangling the web of interrelated drivers of land use changes and how agricultural production can be increased without causing further damage to the environment. The chapter then turns to reveal the microeconomic overview of agricultural smallholders, whoplay a critical role in all agricultural production in Indonesia but are experiencing a decline of their household income. All of these issues are clearly summed up at the end of the chapter with some recommendations for future agriculture in Indonesia.
Chapter 5 takes a different angle on rural issues by focusing more on the issues of community participation through a national program known as CDD (Community-Driven Development). The chapter analyses the example of a large-scale, donor-driven program called the National Program of Community Empowerment (Program NasionalPemberdayaanMasyarakat-PNPM). The objective of this program was initially claimed to empower the poor by giving them control over decisions and management but there were doubts of the effectivenessof the program on the ground. An interesting point that can be taken from this chapter,which would be useful for future community-based programs, is the fact that CDD programs are mostly structured in a formal way. They tend to focus more on the administration and formal procedures of participation. For the sake of effectiveness, CDD programs should allow for more flexible targets beyond merely a checklist of people's participation in meetings. This chapter unveils the dynamics of power relations at the local level which the CDD program often failed to notice. Facilitators also hold a critical role in a CDD program; not only because they have to involve people into the program but they also have to involve themselves into local people's tradition and informal activities. Therefore, they need to acquire a better understanding of the local people's characteristics, perceptions and needs. Challenges and recommendations are elaborated comprehensively in this chapter. However, one thing that I found missing, which could serve as a background to this chapter is why the idea of a bottom-up approachstarted and why numerouscomparable programs emerged within a short period of time.

Moving from the lessons learned from community empowerment programs, Chapter 6 offers a new perspective in understanding inequality in Indonesia that is beyond income and consumption. This chapter starts by re-emphasizing the necessity to assessthe inequality issue not just usingeconomic measures, but also measures such as education, health, and access to basic facilities. Using data from a large national survey called Susenas(National 
Socioeconomic Survey), the chapter discusses various measures of inequality in Indonesia, based on three types of regional segregation: urban vs. rural, Java/Bali vs. outside Java/ Bali, and Western Indonesia versus Eastern Indonesia. Furthermore, unlike previous studies, the chapter looks at inequality both within and between four major ethnic groups: Javanese, Malay, Bugis and Chinese. The chapter meticulously explains examples of inequality and whether there are any significant differences between ethnic groups. Since the analysis within this chapter is derived, to a great degree, from secondary data and a quantitative approach, further research on the ground complemented with more in-depth analysis would provide greater benefit to understanding the issue of inequality in Indonesia.

Another study at the macro level is presented in Chapter 7.This study looks at I998 when Indonesia, after nearly thirty years of stable growth, experienced a severe economic crisis. The government, in an attempt to minimize the negative impacts of the crisis created targeted programs which acted as a "safety net" for the population. One program that is discussed in this chapter is the Social Safety Net Program,locally known as JPS (JaringPengamanSosial). The chapter discusses a brief history of the economic breakdown, the solution of a targeted program (JPS) and how the central government struggled to design and allocate their budget to all regions in an equal manner. Eventually four major areas were selected under JPS: food security, job opportunities, education and health. Unfortunately, the chapter doesn't provide much detail on the background criteria for thisselection. Similarly with the previous chapter, the analysis for this chapter is heavily based on a quantitative approach using household data as the unit of measurement from two major surveys: The National Household Survey (Susenas) and a panel survey conducted by the Central Bureau of Statistics (BPS) and UNICEF. The analysis of this chapter is laborious and exhaustive and might overwhelm readers who don't possess a quantitative background. However, the charts and tables are usually accompanied by descriptions that are easy to digest.
Chapter 8 presents another Indonesian government program that aimed to empower the community, specifically micro, small and medium scale enterprises. It is called the Program of the Application of Science and Technology, in the Regions to Empower Micro, Small and Medium-Scale Enterprises, and is a collaborationwith the government research institute, LIPI (Indonesian Institute of Sciences) and is commonly referred to as IPTEKDA-LIPI. It was established in 1998. The chapter introduces the key role of small, medium enterprises (SMEs), the vulnerability of SMEs, and also emerging challenges to help out the "real" SMEs. The chapter outlines some of the problems, such as the misperception that SMEs owners only include those SME's owned by indigenous Indonesians (pribumi), who are economically weak groups.But SMEs can also be owned by non-indigenous (non-pribumi), known as Sino Indonesians, who are often a stronger economic group. Moreover, the chapter then highlights the role and challenges of the IPTEKDA -LIPI program and how it has improved overnearly 20 years. One valuable lesson conveyed from this chapter is that when it comes to empowering communities, the program should be educational-based instead of charity based so that SMEs can be, as quoted from the text, 'viable and dynamic firms'.

Chapter 9 provides us with a lesson learned from the much recognized international conference, the I955 Asia Conference which was held in Bandung, the home of Joan Hardjono. The chapter assesses the prominence of the Bandung conference in a contemporary political and economic context, not only in Indonesia, but in the other participating countries as well, including China, India and the African countries. A valuable message that can be derived from this chapter is that past events can become a useful reference in shaping international affairs and foreign policy of a nation. To play a significant role on the international stage, a country should address major issues that are happening at the present as well as planning for what will happen in the future.

Alternative or new employment opportunities were foreseen by Joan Hardjono as an essential issue, especially in the case of 
an agriculturally dense population such as rural Java where, in parallel, landholdings areexperiencing a decreasing trend. Chapter Io, like some other chapters in this book, touches upon the effect of the Asian Financial Crisis (AFC)on Indonesia where Indonesia's industrial development collapsed. It isa comparison study of the pre- and post-crisis periods at the macro level,closely examining unemployment and wages. The data is mostly derived from the National Labour Force Survey and analysed using a quantitative approach. Interestingly, when discussingunemployment, the chapter details the increase of under employment in Indonesia after the AFCwhich should not be under estimated. Moreover, the chapter not only explains the changing pattern of employment from three major sectors: agriculture, manufacturing and services, but also the emergence ofinformal and casual employment. Demographic characteristics such as gender and level of education are also discussed in the analyses. In the end of the chapter, some valuable thoughts and cautions are given especially on the dualistic pattern of job creation.

Chapter II raises issuesfaced by the rural community from a population perspective, specifically the dynamics of youth in rural areas. The chapter touches upon the important role of youth in development and the different definitions of youth from various sources. The chapter then turns to highlight the prolongation of youth in Indonesia due to longer involvement in education. The most interesting discussion in this chapterisabout how higher education of rural youths affects the transition away from agriculture and other rural sectors, which are commonly equated to lower education levels, and how government is managing it.This can be summarized by the quote from the text: "Where will the needed jobs for young, relatively educated rural people come from?". The chapter maps out the interrelated issue of youth migration, not only geographical-wise but also employment-wise and the reasons for this. Readers might question the solutions offered by this chapter, the author admits that it doesn't provide an obvious answer, but underlines that the intention is to provide readers with examples of rural youth problems from recent studies and the importance of addressing them for the future of Indonesian rural youth and the agricultural sector.

Chapter i2,would be favourable reading for those whose work constellates around labour issues. The dynamics of employment and labor conditionsis vigorously discussed in other chapters but this chapter looksat the issue from a policy point of view. Firstly, it assesses the processes of Indonesia labour policy and Bappenas' take on the prolonged debate of Law No 13/2003. Afterwards, it discusses the shift of global manufacturing, which drastically changed the strategy of employers and caused major loss of job opportunities. This chapterconcludes with some important thoughts on the existence of power relations and the critical need to protect marginal people from future changes to the labour market.

Last but not least, Chapter I3 sums up the overall discussion about the impact of the macroeconomic crisis to rural society by conducting a comparison study between Indonesia and other Southeast Asian countries. From the very beginning, the chapter emphasizes that crisis is "an ever-present feature of the global economy". Therefore, how a country reacts to a crisis is very important as it reflects their quality and resilience. These can be seen by examining a list of outcomes over two periods of crisis (I997-98 and 2008-09) which are displayed in Table I3.I. The table provides evidencethat Indonesiawas better prepared and better regulated when the later crisis occurred.The chapter carefully observes the reasons behind Indonesia's better management in dealing with crisis, apart from as the author states, "elements of good luck". Towards the end of the discussion, the chapter relates the impact of crisis back to Joan Hardjono's main concerns: the strong relationship between poverty and agriculture and the intensity of this relationship which requires further rigorous evaluation.

ANDINI DESITA EKAPUTRI

Researcher, Research Center for Population, Indonesian Institute of Sciences (LIPI). PhD candidate at University of Hawaii, Manoa. Email address: andio29@lipi.go.id 